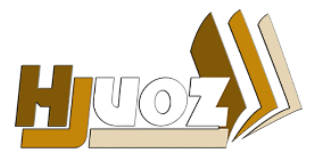

hjuoz.uoz.edu.krd p-ISSN: 2410-7557 e-ISSN: 25185128
كَوْقارا زانستيّن مروَقايهتى يا زانكوَيا زاخوّ

مجلة العلوم الانسانية لجامعة زاخو مروفين

Humanities Journal of University of Zakho (HJUOZ)

Vol. 5, No. 4, pp. 1061-1068, December-2017

\title{
الحياة الاجتماعية و الاقتصادية للطبقة العامة في المجتمع العراقي في العصر العباسي
}

\author{
محمد صديق حسن \\ قسم التاريخ، فاكولتي العلوم الإنسانية، جامعة زاخو، اقليم كوردستان - العراق.

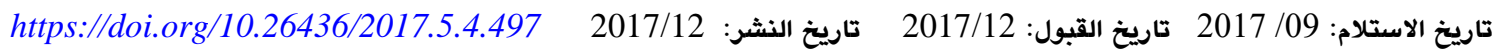

الملخص:

دراسة المجتمع الاسلامي من موضوعات التاريخ المهمة، والتي تكشف عن مظاهر الحضارة الاسلامية والتي لم تكرس لها جهود كافية للكشف عنها وإبرازها للوجود وكما أبرزت بعض صفحات تاريخنا المشرق التركيب الاجتماعي لطبقات المجتع الاسلامي المتعددة، لذا استمد البحث تلك المادة من مظان متعددة وتناول التاريخ الذي صنعه المجتمع العراقي وخاصةالطبقة العامة منه، والتي تضم في تكوينها الصناع والحرفيين والزراع ومختلف الاصناف في المجتمع كاصحاب المهن من الدباغين والحماليين والسماكين وياعة الدقيق والسقطات وغيرهم كثير كالعيارين والشطار، وكانت هذه الطبقة مغلوبة على امرها تميزها مظاهر الطبقة الفقيرة وهي الفقر والحرمان والفاقة والحاجة

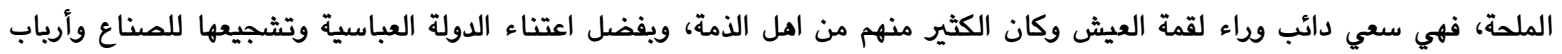
الصرف اصبحت لبعض الصناعات العراقية شهرة عالمية وخاصة الصناعات النسيجية وكذلك المزارعين من سكان القرى والارياف في العراق

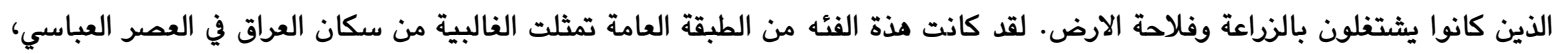
أما العيارون فقد كانوا ينتمون الى طبقات الشعبية الكادحة وهم فئة من العامة اندفعوا الى تحسين احوالهم الاقتصادية المزرية باتخاذ مختلف الطرق من السلب والنهيب والسرقات مستخدمين في ذلك السلاح لتحقيق اهدافهم، وكذلك الشطار الذين هم فئة من العامة ايضا تعمل هي الاخرى في اعمال السلب والنهب وقطع الطرق واستخدام الطرق والوسائل العنيفة لتحقيق مآربهم وقد نشطوا خلال حوادث سنة

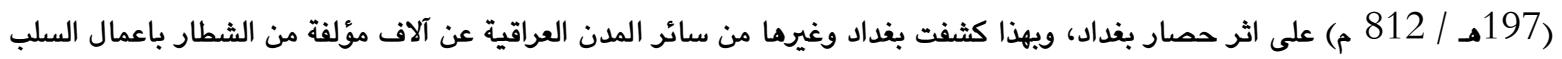
والنهب وقطع الطرقات وهذا ما يدعوا الى ان تلك الاعمال ما هي الا نتيجة لما كانت تعانيه العامة من انحطاطاوضاعها السياسية والاقتصادية،ومع ذلك فقد كانت لهذه الطبقة دورها الكبير في المجتمع العراقي من الناحية السياسية والاجتماعية والاقتصادية.

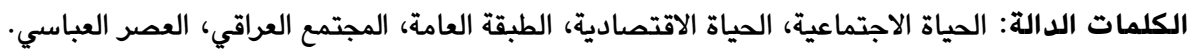

الطبقة الفقيرة وهي الفقر والفاقة والحاجة الملحة، فهي في سعي دائب وراء لقمة العيش، ومع ذلك فان مذه الطبقة كان لها دورما في المجتمع رغم ان طبقة العيارين والشطار كانت مصدر ازعاج لغيرما من الطبقات فان هؤلاء اللصوص و قطاع الطرق كانوا يضطرون الحكام على ابداء الاصلاح لانهم لم يلجئوا الى ذلك الا بدافع الحاجة الشديدة، ان الصناع والحرفيين وصفوا بالعمل اليدوي والجهد العضلي كانوا يعملون من خلال مهنهم المنوعة في التصوير والصفر والنقش والصبغ وغير ذلك، وغرضهم في ذلك هو اصلاح احوالهم المعيشية، وكانت طبقة الزراع تضم الى تكوينها المزارعين وهم سكان القرى والأرياف في العراق وكانوا يشتغلون بالزراعة وفلاحة الارض، وكانت تمثل الغالبية العظمى من سكان العراق في العصر العباسي. و ينتمي العيارن الى هذه الطبقات الشعبية الكادحة وهم فئة من العامة، اندفعوا المى تحسين احوالهم
1

دراسة المجتمع العربي الاسلامي من موضوعات التاريخ الهامة، التي تكثف لنا عن مظامر الحضارة الاسلامية التي لم تكرس لها جهود كافيةللكشف عنها وابرازما للعيان.وقد ابرزت بعض صفحات تاريخنا المشرق التركيب الاجتماعي لطبقات المجتمع الاسلامي المتعددة فاستمد هذا البحث تلك المادة من مظان متعددة وتناولالتاريخ الذي صنعه المجتمع العراقي وخاصة الطبقة العامة منه والتي تضم في تكوينها الصناع والحرفيين والزراع والفئات الدنيا من المجتمع كاصحاب المهن الوضيعة في نظر المجتمع آنذاك كالسقائين وياعة الدقيق والسماكين والنخاسين والدباغين والحمالين وغيرهم كثير كاللصوص وقطاع الطرق والعيارين والشطار وهذه الطبقة مغلوية على امرها تميزها ابرز سمات 
خاص به وممارسة صنعته بصورة مستقلة (17)، ويليه المبتدأ وهو الذي ينتمي الى الصنف ويتدرب على ايدي الصانع (18). وقد أدت التنظيمات الى نشأة النقابات التي كانت تستهدف تبادل المعونة والدفاع عن مصالحهم (19)، وكان لامل المهنة الواحدة عُرفٌ جارِ بينهم فذكر ان جماعة من الغزاليين اختصموا الى شريح القاضي في شيئ فقالوا: "سنتنا بيننا كذا وكذا، فقال: سنتكم بينكم" (20)، وكان الصناع في العصر العباسي الاول يمتلكون حوانيت خاصةبهم يعملون فيها وكان البعض منهم يعمل بأجرة يومية عند اصحاب الدكاكين وغالبا ما كان اصحاب الدكاكين والصناع يقضون اوقاتهم في بيع منتجانهم في الاسواق كما في العصور الوسطى الاوروبية،حيث كانت تباع كل سلعة معينة في سوق خاص بها (21)، وييدوا انه لم يكن هناك حد ادنى لمستوى الاجور اليومية، بل كان الامر متروكاً للاتفاق بين العامل وصاحب العمل ويتم ذلك قبل البدء في العمل(22)، وقد اثير الى العمال الذين كانوا يشتغلون باجرة يومية مضمونة وليس بالانتاج لا يخلصون في عملهم فكثيرا ما كانوا يضيعون بعض الوقت من العمل "اما بالتبثط، اي: التباطؤ في العمل او اصلاحآلات العمل،مثل ان يحد النجار الفأس والشقاق والمنشار" (23)، وان مثل هذة الاساليب كانت تشكل نوعا من الخيانة لصاحب العمل ومع ذلك


المسؤول عن امر العلاقة ما بين العامل ورب العمل "فاذا تعدى مستاجر على اجير في نقصان اجره، او استزادة عمل كف عن تعديه، وكان الانكارعليه معتبرابشواهد حاله" (25)، وقد ظهر في العصر


قيامهن باعباء بيتوهناليومية (26)، كاشتغالهن بأعمال الغزل (27)، والبعض كخبازات في بيوت الموسرين لقاء اجر معلوم (28)، ويفضل اعتناء الدولة العباسية وتشجيعها للصناع وأرباب الحرف اصبحت لبعض الصناعات العراقية شهرة عالمية وخاصة ما يتعلق بالصناعات النسيجية فقد اشتهرت محلة العتابين ببغداد بنسيجهالحريرى الذي اكتسبشهرة عالمية بذلك، حتى ان بعض مدن الاندلس انشات مصانعا او دوراً النيسج فيها كالعتابي (29)، الذي سميت بهذا الاسم تقليدا كالثياب التي كانت تنتجها محلة العتابية ببغداد(30)، واشتهرت محلة التستريينبيغداد بعمل الثياب التسترية (31)، ولهذا وصفت صنائع بغداد بانها أفخر الصنائع (32)، ووصف صناعها بانهم اهل البراعة في كل صناعة(33)، كما اشتهرت مدينة الموصل بصناعة النسيج الموصلي الذي عرفه العالم باسم الموسلين Moseline(34)، الى جانب هذة الصناعات كانت منالك صناعة الستور والبسط (35)، والأُر والعمائم الرفيعة وألوان المناديل السامانية (36)، وكذلك هذان
وتوصلوا في ذلك بالنهب والسلب والسرقات، مستخدمين السلاح وكذلك الشطار فهم فئة من العامة تعمل هي الاخرى على السلب والنهب وقطع الطرق واستخدام القتل وغيره من الوسائل العنيفة. كانت الطبقة العامة في المجتمع العراقي في العصر العباسي الاول تتكون من الشرائح الاتية:- - م

\section{2.الصناع و الطوائف الحرفية}

هم طائفة من الناس وصفوا بانهم يعملون بأبدانهم وأدواتهم في مصنوعاتهم المكونة من الصود والنقوش والاصباغ والاشكال وغرضهم طلب العوض عن مصنوعاتهم لصلاح معيشة الدنيا (1)، وكان الصناع يقسمون من حيث العمل اللى فئتين الاولى تضم المشتغلين بأجرة وهم الصناع الذين يعملون في المؤسسات الخلافية، وفي دود الضرب او في المحلات التجارية الكبيرة، والثانية يشتغلون لحسابهم الخاص بما في ذلك المبتدئين (2)، وعلى رغم من ان الصنائع كانت وراثية يأخذها الابناء عن الاباء (3)، الا ان الافراد كانوا يخيونن في المهنة التي يريدون مزاولتها (4)، ولكن الابناء اذا تعلموا صنعة آبائهم وجدادهم حذقوما ويرعوا فيها (5)، ولا يمكن ان يجاريهم المبتدئون. ويبدوا ان معظم المشتغلين في الصناع كانوا من اهل الذمة فقد جاء ان اكثر الخياطين والصباغين والاساكفة والخرازين كانوا من اليهود بينما كان اكثر المسيحين صيارفة وتجاراً، ومع ذلك فقد كانت روح التسامح تسود بين مختلف الفئات(6)، كما اشتغل في الصناعة عدد كبير من الرقيق الذين كانوا يُشترون من قبل اصحاب الصنائع كل حسب اختصاصة، فمنهم الصباغون والخياطون والقصارن(7)، والاساكفة والحدادون والرفاؤون والمطرنون والنجارون والوراقون والعطارن وغيرمم (8)، وكان من الطبيعي ان تقوى الرابطة الاجتماعية بين اصحاب الصنائع المختلفة ويشعر كل صانع برابطة الانتماء الى اصحاب حرفته وصنفه (9)، وقد ساعدهم هذا الشعور على ان يجتمع اصحاب حرفة منهم في سوق واحدة بالنسبة لمختلف المهن متبعين في ذلك مأثور قولهم "الصناعة نسب" (10)، ويلغ التماسك حد العصبية للمهنة الواحدة والاعتزاز بها (11)، ومما يشير الى تعاونهم و تضامنهم

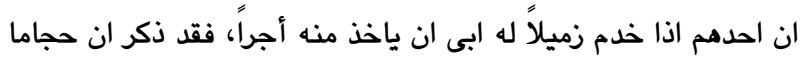

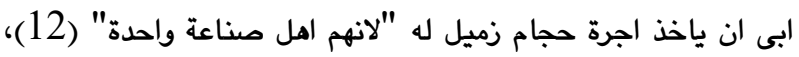

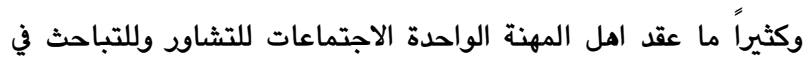
امور مهنهم (13)، و لقد ظهرت تنظيمات لاهل الحرف فكان لكل حرفة رئيس من اصحابها تعينه الحكومة وتعترف به و يسمى شيخ الصنف(14)، او الرئيس (15)، ويليه الاستاذ (16)، وهو المقدم في الصنف يأتي الصانع وهو الذي تعلم المهنة ويستطيع فتح حانوت 
مياهه من نهر الفرات ايضا ويسقى بها المناطق الزراعية الواقعة في الجهة الغربية من مدينة بغداد (47)، وكان يتفرع من نهر عيسى فروع كثيرة كنهر الصراة الكبير الذي يصل الى الجانب الجنوبي الغربي من المدينة المدورة (بغداد)عند الجسر القديم بالقرب من باب الكوفة، ومن هنا ينحرف حول سور المدينة فيمر من امام باب البصرة ويستمر في الجريان نحو الشمال الشرقي مسافة قصيرة،حتى يصب في دجلة تحت بساتين قصر الخلد التي تقع خارج باب البصرة (48)، وكان يتفرع منه انهار كثيرة لعمارات الناحية (49)، اما الانهر الاخرى التي كانت تتفرع من نهرعيسى فهي "نهر رزين، ونهر البزازين،ونهر الدجاج، ونهر القلائين" (50)، و يقال ان الذي فتح هذة الانهر هو الخليفة ابو جعفر المنصور لإرواء منطقه الكرخ (51)، هذا الى جانب الانهار العديدة التي كانت تاخذ مياهها في نهردجلة وتسقى بها الاراضي الزراعية الواقعة في الجهة الشرقية من هذا النهر،اهمها:نهر النهروان الذي يتفرع من الجانب الايسر من نهر دجلة قرب سامراء،فيمتد بمحاذاة نهر دجلة من جهة الشرق مسافة اكثر من مئة كيلومتر، حتى يلتقي اخيرا بنهر دجلة بالقرب من اراضي مدينة الكوت الحالية (52)، وعلى هذا النحو ازدهرت الزراعة وانتعشت حالة الزراع بفضل اهتمام الخلفاء العباسيين بهذه النواحي الزراعية.وقد كانت الحاصلات التي ينقلها الزراع من قراهم الى الاسواق كثيرة ومتنوعة منها: القمح، والشعير، والارز، والبلح، والسمسم، والقطن،والكتان (53)، ومن الفاكهة انواع كثيرة و متعددة منها البطيخ(54)، والتين (55) والتفاح، والكمثرى، والخوخ(56)، اما من ون ناحية الثروة الحيوانية فكانت كثيرة وذلك لموازاتها مع الزراعة فكلما كانت الزراعة متطورة وكثيفة ومتنوعة يصاحبها كثرة الثروة الحيوانية ايضا وهذا معروفٌ من الناحية الاقتصادية في الفترات التاريخية، وكانت الثروة الحيوانية تمثل الدواب مثل المواثي (57)، وكذلك الجاموس(58)لتوفرمياه الانهار، وكما هو معروف ان الجاموس يعتمد كثيرا على مصادر المياه وقضاء فترات طويلة في الغطس بالمياه. بالاضافة الى انواع من الطيور الداجنة بصورة عامة (59).

\section{4. - 4. - 1العيارون}

هم طائفة من الطبقة العامة برنوا في اواخر القرن الثاني الهجري/ الثامن الميلادي ويالتحديد اثناء النزاع بين الامين والمامون وعلى اثر حصار بغداد سنة (197هـ/812هم) من قبل الجيوث الطاهرية الخرسانية،حيث استنجد الخليفة الامين بطائفة العيارين بعد ان عجز جنوده عن الدفاع عن بغداد،ومنذ ذلك التاريخ ظهر العيارون على مسرح الاحداث، ويبدوا انهم اتخذوا لانفسهم اسم الفتيان بدليل ان كلمة الفتى اصبحت مرادفة لكلمة العيار،كما وصف شجاعتهم أحد شعراء بغداد بالقول:
اثتهرت البصرة بصناعة الصابون والزجاج(37)، ومدينة الكوفة بكوفياتها الصريرية (38)، وكانت هذة المنتجات الصناعية تباع عن طريق الوكلاء والتجار.

\section{3.المزارعين}

وهم سكان القرى والارياف في العراق وكانوا يشتغلون بالزراعة وفلاحة الارض، ولا شك ان المعلومات عنهم خاصة فيما يتعلق بطرق حياتهم اليومية وحياتهم الاجتماعية قليلة لعدم اهتمام الكتابوالمؤرخين بهذه الناحية،لقد كانت مذة الفئة من الطبقة العامة وتمثل الغالبية العظمى من سكان العراق في العصر العباسي الاول، ويبدوا انهم لم يمتلكوا الاراضي الزراعية بل كانو مزارعين بأجر او عقود، بدليل ان الاراضي الزراعية الشاسعة كانت بيد رجالات الدولة وشيوخ القبائل العربية حيث ورد: "ان العرب ملكوا الضياع والاراضي ونرعوا الارض مالا تجاسر الاكرة على زراعته وطالبوا بالخراج" (39)، ولا نستعبد ان يكون العبيد الزنج الذين جلبهم العباسيونويقايا الزط الذين جلبهم الحجاج بن يوسف الثقفى هم الذين اشغلوا بالزراعة (40)، ومما شجع الناس علىالاقدام على مهنة الزراعة هو كثرة الارباح من غلات الاراضي، وقد قدرت غلة الخيزران من ضياعها بــ"مئة الف الف وستين الف الف درهم " (41)، وقد وجه الخلفاء العباسيون عنايتهم الى تشجيع الزراعة وتحسين حالة الزراع لانهم كانوا يعتبرون ازدمار الزراعة وفلاحة الارض من اول الواجبات التي يفرضها الدين الحنيف (42)، فضلا عما كانت تدره من ارباح كبيرة لبيت مال المسلمين، فوضعوا المشاريع والخطط الزراعية التي من شانها زيادة الانتاج الزراعي ويالتالي زيادة دخل الدولة وتوفير حياة افضل للزراع، ومنع الزراع من الهجرة الى المدن خشية تناقص الايدي العاملة في القرى (43)، ثم عملوا على اتباع سياسة حكيمة ترمي الى عدم ارهاق المزارعين بالضرائب، واول من اهتم بذلك من خلفاء بني العباس هو الخليفة ابو جعفر المنصور، فقد ألغىالضريبة النقدية التي كانت تفرض على الحنطة والشوفان وأحل محلها نظام "المقاسمة" وهو دفعالضرائب نوعابنسبة خاصة من المحصول، على ان النظام النقدي القديم ظل على النخيل والفواكه وأشباهها، وحين تولى ابنه المهدي الخلافة قام بتطبيق النظام الذي ادخلة ابوه من قبل(44)، ولما كان الماء ضرورياً لقيام زراعة ناجحة بذل الخلفاء العباسيون وعلى رأسهم ابو جعفر المنصور جهدهم من اجل ايصال المياه الى اراضي الزراعية كافة،فقتحوا القنوات الجديدة وطهروا الترع القديمة وكان اول هذة القنوات نهر الرفيل "الذي ياخذ مياهه من الضفه اليسرى لنهر الفرات عند قنطرة دمما" (45)، ومنالك نهر اخر سماه اليعقوبي "نهرعيسى الاعظم" (46)، نسبة الى الامير العباسي عيسى بن علي،وكان يأخد 
راماه مدة طويلة حتى فنيت سهام القائد، وظن ان العريان فنيت حجارته، فرماه بحجر في المخلاة، وقد حمل عليه القائد، فما أخطأ عينه، وثناه بحجر آخر، فكاد يصرع القائد عن فرسه، ووقعت البيضة

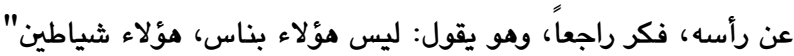
(71)،والى جانب مذه التنظيمات العسكرية كانت لهم تنظيمات مدنية،فكان منهم الشيخ والاستاذ (72)،والاستاذ عندهم اعلى مرتبة في التنظيم، ثم الرئيس (73)، وهو الذي يرأس المجموعة من الفتيان الذين هم بمثابة تلاميذ يدريهم على اعمال العيارة (74)، ويشير الجاحط الى وجود قاض للفتيان وهو ابو الفاتك (75)،وكان لهم مراسيم خاصة يتبعونها عند احتفالهم بانتماء اعضاء جدد في زمرتهم فكانوا يُلبسون العضو الجديدسراويلخاصةتسمى: "سراويلالفتوة" (76)،ويشريون أنخاباً من النبيذ احتفاءً بهذا العضو الجديد (77)، وكانوا يمتدحون بكثرة الشباب في مثل هذه المراسيم (78)، واخذ العيارون يزدادون القوة بقدر ما كانت الدولة العباسية تزداد ضعفا و خاصة في اواخر العصر العباسي الاول و بداية العصر العباسي الثاني، فتكاثرت مجماتهم واعتداءاتهم على المدن العراقية عامة وعلى بغداد خاصه،فكانوا يسلبون عمائم الناس وياخذون ثيابهم من الحمامات علنا، ويقتلون من ظفروا به من اتباع صاحب الشرطة،وينهبون الدكاكين وصار الناس منهم في ويل عظيم (79). ومن الغريب انه الى جانب هذهالاعمال اللااخلاقية التي كانوا يقومون بها ترى بعض الصفات الحسنة الخاصة بهم فقد ذكر عن ابي الفاتك وهو قاضي الفتيان انه قال: "الفتى لا يكون نشالا، ولا نشافا، ولا مرسالا، ولا نكافا، ولا مصاصا،ولا نفاضا، ولا دلاكا، ولا مقورا، ولا مغربلا (80)، فقد روى التنوخي عن ابن حمدون - وهو احد رؤساءهم - انه كان لا يتعرض لاصحاب البضائع القليلة التي يكون دون الالف فاذا تعرض لقليلي الامكانيات قاسمهم عليه وترك شطر ماله في ايديهم، وانه لم يكن يفتش امراة ولا يسلبها (81)، وكان ابن حمدون مذا يعلل سبب قطعه الطريق واخذه اموال الناس بان السلطان قطع ارزاقهم فأحوجهم الى هذا (82)، ويتضمن هذا دليلا اخر على الدوافع الاقتصادية التي تكمن وراء حركتهم كلها.

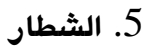

هم فئة من العامة نشطوا خلال حوادث سنة (197 هـ / 812 م) وعلى اثر حصار المامون للامين في بغداد ويهذا كشفت بغداد وغيرها من سائر المدن العراقية عن آلاف مؤلفه من الشطار الذين لا يملكون من اسباب العيش غير ادوات الجريمة فقاموا بحركات تشبه الى حد كبير حركات العيارين التي قاموا بها في مثل هذه الظروف، وهذا ما حدا بكثيرمن
ليس يدرون ما الفـــــرار اذا الابطال عاذوا من القنا بالفرار واحد منهم يشـــد علـــى ألفين عريان مـــــــاله مـــــن ازار

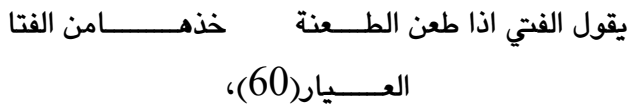

وقد قام العيارون بحركات اجتماعية تهدف الى تحسين احوالهم بالعديد من الطرق كالنهب والسلب والسرقات، مستخدمين السلاح فقد كانوا يشعرون بانهم مهملون من قبل اصحاب النفوذ والسلطة وان ظرفهه المعيشية سيئة للغاية، ولهذا اندفعوا بتاثير الحاجة وظرفهم الاقتصادية الصعبة الى القيام بسرقة الحوانيت والاسواق وييوت الاغنياء (61)، لذلك فقد كانت حركاتهم شعبية تمثل صراعاً طبقياً، ولاقت حركتهم تأييداً وقبولا شعبياً باعتبارها تدعوا الى تطبيق فكرة العدالة الاجتماعية المساواة والقضاء على التوزيع غيرالعادل للثروة بطرق غير مشروعة (62)، و ذهب احد المؤرخين الى تعليل حركة العيارين برغبة الطبقة المحرومة في اخذ ثأرها من الاثرياء (63)، ومما يؤكد ذلك ما جاء على لسان الخليفة الامين حين قال: "وددتُ ان الله قتل الفريقيين جميعا فأراح الناس منهم،فما فيهم الاعدو لي، اما هؤلاءفيريدون مالي، واما اولئك، فيريدون نفسي" (64)، وييدو ان اكثر العيارين كانوا من غير العرب كما يستدل ذلك من اسمائهم من أمثال: نبتويه، وخالويه،ويكويه، كما يبدو ايضا ان اعدادهم كانت كثيرة فقد ذكر انهم عندما ثاروا في بغداد لنجدة الامين بلغوا نحو مئة الف(66)، ومما يشير ايضاً الى كثرة عدد العيارين ماقيل عنهم بأنهم كانوا "اذا تحركوا من بغداد ملكوا" (67)،وكانت لهم تنظيمات عسكرية أشبه بتنظيمات الجيوش،فكان على كل عشرة منهم عريف، وعلى كل عشرة عرفاء نقيب، وعلى كل عشرة نقباء قائد، وعلى كل عشرة قواد امير(68)، واتخذوا لانفسهم رسوماخاصة لتميزهم عن غيرهم فكانوا يقاتلون عراة وفي اوساطهم مآزر واتزروا لرؤوسهم ودواخل من خوص سموها الخوذ، وورقاً من الخوص والبواري قد قرنت وحشيت بالحصى والرمل (69)،وكان من اسلحتهم المقاليع والحجر الى ملى جانب السيوف والاقواس والرماح(70)،وعلى الرغم مما كان ينقصهم من الخبرة العسكرية فقد امتازوا بالصبر وثدة البلاء والجلد في المواقف الحرجة وفي النكبات، كما عرفوا بمهارتهم في رمي الحجر بالمقلاع، فقد روى المسعودي ان أحد قادة الفرسانسأل أميره طاهر بن الحسين "ان يجعل له الحرب في يومها له فيه، ففعل طامر له ذلك، فخرج القائد وقد حقرهم وقال:ما يبلغ من كيد هؤلاء ولا سلاح معهم، مع ذوي البأس والنجدة والسلاح والعدة؟فبصر به بعض العراةوقد 
الامراء والاستنارة بالعلم والادب فقد ذكروا ان "ابن سيار كان يتزي بزي الامراء لا بزي القطاع، وكان كلامه يدل على فهم و ادب، وهو رجل فاضل يروي الشعر ويفهم النحو"(94). ثم نشطت حركة الشطار و ودهاء تزايدت زيادة ملحوظة في اعقاب الاضطراباتالتي حدثت في سنة (201هـ/ 816م) على اثر خلع العراقيين للخليفة المأمون ومبايعة عمه ابراهيم بن المهدي بالخلافة فاشتد نشاطهم في هذه الفترة حتى نال الناس منهم ضرد عظيم، واستلزم الامر ان فريقا من الناس جندوا انفسهم لمدافعة هؤلاء الشطار الذين افسدو الحياة في العراق عامة ويغداد خاصة بعد ان عجزت السلطة في الحاكمة عن القضاء عليهم لانشغالها بالازمة السياسية العصيبة، فقد ذكر المؤرخون ان رجلا يدعى خالد

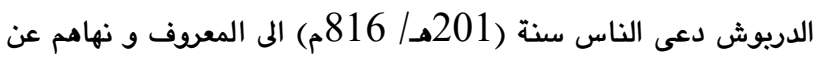
المنكر واجاب خلق كثير منهم وقاتل اهل الزعارة فغلبهم واطلق يدهم فيهم بالعزم والتنكيل، وخلفه رجل اخر من اهل سواد بغداد يعرف

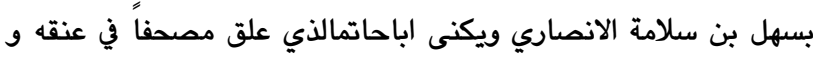
امر الناس بالمعروف و نهاهم عن المنكر ودعامم الى العمل بكتاب الله تعالى وسنة نبيه صلى الله عليه و سلم، فاتبعه الناس كافه بين الشريف والوضيع و نزل قصر طاهر، واتخذ الديوان وطاف بيغداد ومنع كل من اخاف المارة ومنع الخفارة لاولئك الشطار (95)، وعلى هذا النحو اخذت حركة الشطار في العراق تنقرض تدريجيا، حتى تلاشت بفضل الحركة المضادة التي قامت بها الامالي ممن دفعتهم الغيرة على مصالحهم، والرغبه في توطيد دعائم الامن في وقت سادت فيه الفتن والفوضى في

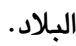

\section{6.الخاتمة والاستنتاجات.}

بعد مذا العرض الموجز عن الحياة الاجتماعية والاقتصادية للطبقة

العامة في المجتمع العراقي في العصر العباسي تبين لنا ما يلي: 1 - ان الدراسات التاريخية من النواحي الاجتماعية والاقتصادية لها اهميتها، إذ انها تكشف عن المظاهر الحضارية بصورة عامة، بالاضافة الى الظواهر الاخرى.

2 - ان المجتمع العراقي في العصر العباسي كان مجتمعا طبقياً، وبين هذه الطبقات فوارق اجتماعية واقتصادية كبيرة بين الطبقات ويون شاسع بين الموسرين والفقراء سببها فقدان العدالة في توزيع الثروة. 3 - كان للطبقة العامة في المجتمع العراقي دور كبير في مسيرة الاحداث السياسية اضافة الى الجوانب الاقتصادية.
المؤرخين الى الخلط بين الشطار والعيارين، لقد قام شطار باعمال السلب والنهب وقطع الطرق التي لم تكن في نظرتهم من اعمال اللصوصية، وانما كانوا يعدونها حرفة مشروعة باعتبار انما يستولون عليه من اموال التجاروالاغنياء هي زكاة تلك الاموال التي اوصى الاسلام باعطائها للفقراء (83)، وهذا ما يدعوا الى تلك الاعمال ماهي الا نتيجة لما كانت تعانيه عامة من انحطاط في الحياة السياسية والاقتصادية (84)، وقد اتبع الشطار وسائل واساليب خاصة لاجتذاب الاتباع الى جماعتهم ودعوة الشباب الى الانخراط في صفوفهم وقد عبر الجاحظ عن ذلك بقوله: "وان الشطار ليخلوا احدهم بالغلام الغرير فيقول له:لا يكون الغلام فتى ابدا حتى يصادق فتى والا فهو تكش، والتكث عندهم الذي لا يؤدبه الفتى ولم يخرجه" (85)، فيتاثر الغلام بسرعة اذا كان له ادنى ميل الى الفتوه،وقد اوصى عثمان الخياط وهو احد رؤساء الشطار اللصوص، فقال: عليكم باتخاذ الغلمان، فان غلامك هذا انفع لك من اخيك واعون لك من ابن عمك (86)، وكان من عاداتهم لبس الازار وثرب النبيذ وان شريهم نخب القادم الجديد والاثارة الى الازار تنبئ عن مراسيم خاصة للانتماء اليهم (87)، وقد اشير الى انهم كانوا يأتزرن بمئز يعرف بمئزر الشطار كما ان المحلات التي تجري بهاهذه المراسيم كانت بعيده عن عيون الناس (88)، وهم في ذلك يشبهون العيارين، وكانوا يفتخرون بانفسهم ويعتزون بقوتهم وقدرتهم فيقولالواحد منهم:انا الموج الكدر،انا القفل العسر وانا النار، انا العار، انا الرحى، اذا دار مشيت اسبوعين بلا رأس، و اكلت جميع ما في قدود الهراس اقطف راسك واجعله زر قميصي استقيك فلا اعطشك الا في الجحيم ويلك لو كلمني الفيل لم يجرس،او البحر لم ينبس، او عضني الكلب لم يغرس او زارني النمر ود التقدس، اصدقائي اكثر من خوص البصرة وخردل مصر، وعدس الشام، وحصى الجزيرة، وشوك القاطول، وحنطة الموصل وقصب البطائح، ونبق الاهواز(89). ويبدو ان الشطار كانوا اكثر عددا من العيارين بدليل انهم اكثر انتشارا في الدولة العباسية واطول بقاء منهم(90)، ويفهم من وصية عثمان الخياط انه كان لهم لباس خاص يتزينونبه فمن قوله: "دعوا العمائم، وعليكم بالقناع، والقلنسوة كفر، والخطف شرك" (91)،وكانت لهم تدابير وخطط خاصة بالسرقة فذكر بانهم كانو "يأتون بالرجل يسالونه مالاً يقرضهم او يصلهم فيمتنع عليهم فياخذون جميع مافي منزله" (92)، كما انهم كانو يتبعون الوسائل والخطط الاجرامية عند قيامهم بالسرقة، فكانوا يستدرجون الشخص المراد سلب ما معهبحيلة لايفطن اليها مع التظاهر بالبراءة ومن طباع الشطار الزهد عن حب النساء ايضا(93)، وكذلك الانصراف عن سماع الموسيقى والاستعاضة عن شرب الزبيب المطبوخ بنبيذ التمور واتصفوا من صفات اللصوص، ومن محاسنهم ايضا ارتداء بعضهم ثياب 
143/2 22) البغدادي:تاريخ بغداد (23)



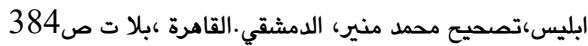

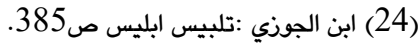

(25) الماوردي ابي الحسن علي بن محمد، الاحكام السلطانية طا طل القاهرة 1929،ص الماودي المي

(26) الغزالي: ابو حامد محمد بن محمد ، احياء علوم الدين ، مطبعة الحلبي و اولاده القاهرة 1938 ، $192 / 3$.

(27) ابن الجوزي : تلبيس ابليس ص384



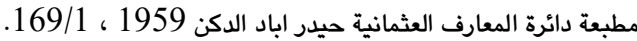

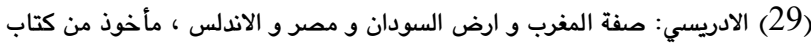

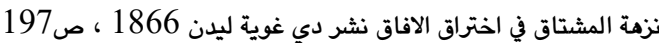

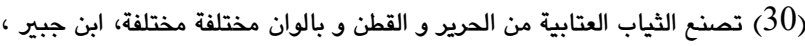

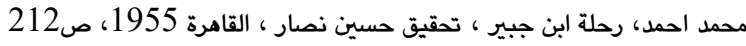

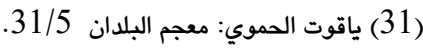
(32) ابن حوقل: ابي القاسم النصيسيني الموصلي ، صورة الارض ، داقد ، نشر دار الحياة

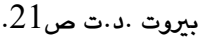

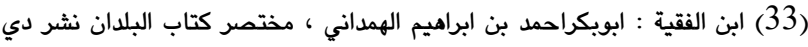

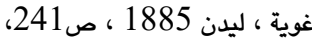

34) Migeons(Gaston): manuol dart musalman vol-11-

(Paris1907 P378.

(35) ابن الفقية : مختصر كتاب البلدان ص 241. (36) كي ، سترانج: بلدان الخلافة الشرقية ، ترجمة بشيرفرنيس و كوركيس عواد،

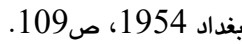
(37) ابن حوقل : صورة الارض ، ص 214 ، المقدسي : ابو عبدالله محمد بن احمد


(38) ابن حوقل : صورة الارض ص 215.

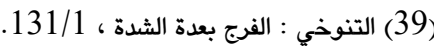

(40) محمود الشريف،حسن احمد ابراهيم :العالم الاسلامي في العصر العباسي


(41) المسعودي : ابي الحسن علي بن الحسين، مروج الذهب و معادن الجوهر تحقيق

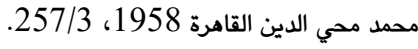

(42) امير علي : مختصر تاريخ العرب ، ترجمة رياض رافت القاهرة 1938 ص .264

(43) احمد صالح العلي : التنظيمات الاجتماعية الاقتصادية ص 88.

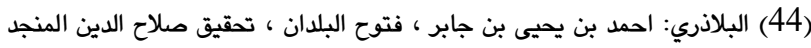

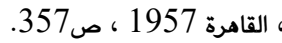
(45) الاصطخري: ابي اسحاق ابراهيم بن محمد ، المسالك و الممالك باعتناء دي ،

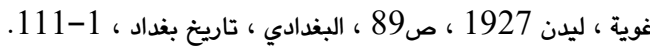

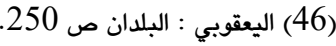
(47) احمد سوسة : فيضانات بغداد في التاريخ ، القسم الاول ، بغداد 1963، ص 213
4 - كان للدولة العباسية دور كبير في تطوير المهن والصناعات، وذلك من التشجيع المستمر والدعم للصناع وأرياب الحرف، فاصبحت للصناعات العراقية شهرة واسعة وخاصة الصناعات النسيجية. 5 - أدت مظاهر الفقر والحرمان والفاقة والحاجة الملحة الى انحدار ثرائح كبيرة من الطبقة العامة الى القيام بأعمال أخرى غير شرعية ومنافية للقيم والاخلاق الاسلامية كأعمال اللصوصية والسلب والنهب وقطع الطرق وغير ذلك، وأدى ذلك الى ظهور العيارين والشطار.

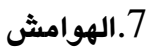

(1) اخوان الصفا:- رسائل اخوان الصفاء و خلان الوفاء ، اعتناء خير الدين الزركلي

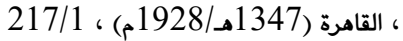

(2) الدوري، عبدالعزيز ، نشوء الاصناف والحرف في الاسلام ، مقالة في مجلة كلية

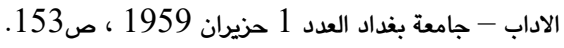
223/1، 3) اخوان الصفا: الرسائل

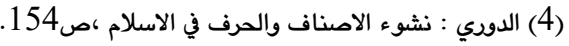
223/1، (5) اخوان الصفا:الرسائل

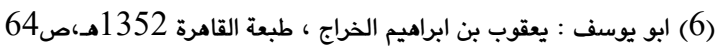
(7)

Dozy; Supplement Aux
DictionnariesArabesBeyrouth1968 Vol2 P365. (8) الصابي : ابي الحسن الهلال بن محسن ، تحفة الامراء في تاريخ الوزراء تحقيق

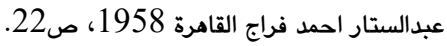
(9) العلي : احمد صالح، التنظيمات الاجتماعية و الاقتصادية في البصرة في القرن


(10) الجهياري : ابي عبدالله محمد بن عبدوس، الوزراء و الكتابتحقيق مصطفى لإنى


(11) الدوري نشوء الاصناف و الحرف في الاسلام ، ص142.

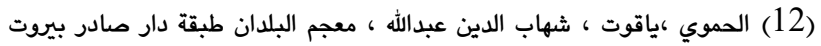
370/1، 1957 (13) البغدادي : الخطيب ، ابي بكر احمد بن علي ، تاريخ بغداد ، تصحيح


(14) اليعقوبي ، احمد بن ابي يعقوب بن جعفر ، البلدان مطبوع مع كتاب الاعلاق

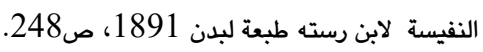
(15) التنوخي: ابو علي المحسن بن علي ، الفرج بعد الشدة ،القاهرة 1955 232/2،

225/1 ، (16) اخوان الصفا:الرسائل 225/1 ، (17) اخوان الصفا: الرسائل 225/1 ، 18) اخوان الصفا: الرسائل

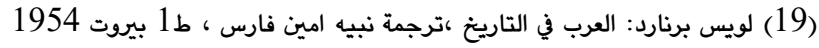
، ص130. (130. (10) (20) وكيع : محمد بن خلف بن حيان ، اخبار القضاة ، تحقيق عبدالعزيز مصطفى

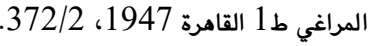

(21) Bartold: The age of the caliphs leiden brill,1960,p53 
(70) الطبري، تاريخ الرسل و الملوك، 458/8، ابن الجوزي، المنتظم في تاريخ الملوك و الامم ، $45 / 8$

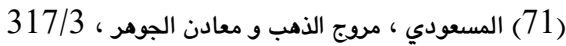

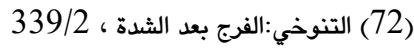

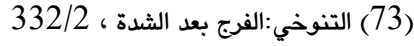

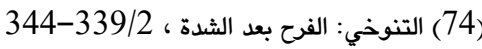

(75) الجاحظ: ابو عثمان عمر بن بحر، البخلاء، ط1 نشر الثرد دار الكتاب العربي- بيروت

1968، صن464

(76) ابن الجوزي، تلبيس ابليس ص378، مصطفى جواد ، الفتوة و اطوارماو اثرها

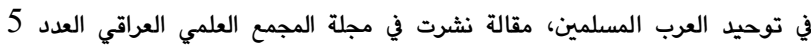
لسنة الس توحيد

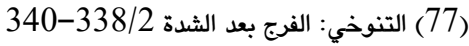

(78) الجاحظ : البخلاء ، ص128

(79) ابن الفوطي: كمال الدين ابي الفضل ، الحوادث الجامعة و التجارب النافعةفي



ص278

(80) - (80) الجاحظ: البخلاء، ص64.

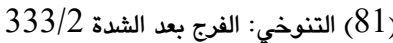

333/2 (82) التنوخي: الفرج بعد الشدة الشرج بعد الشدة

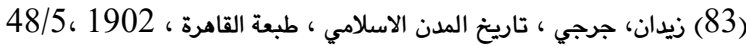

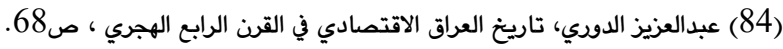



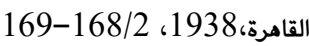

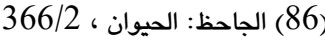

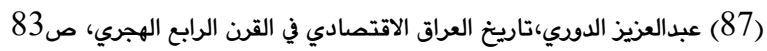

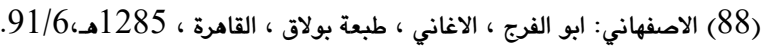

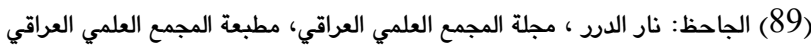

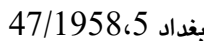

$$
\text { 47/5، (90) جرجي زيدان: التمدن الاسلامي (91) }
$$

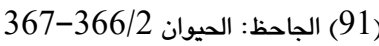

(92) التنوخي: الفرج بعد الشدة، 339/2-340

366/2 ، (93) الجاحظ: الحيوان



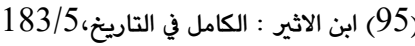

(48) كي لسترانج:بغداد في عهد الخلافة العباسية ،ترجمة بشير يوسف فرنسيس،

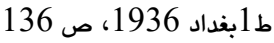

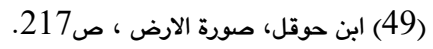





(51) خضري : محمد ، تاريخ الامم الاسلامية ، ط3، القاهرة (52) جواد دسوسة:دليل خارطة بغداد ص30 (53) :

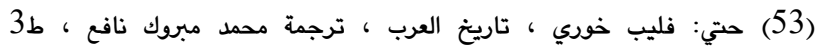

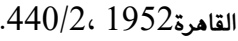

(54) ابن الجوزي:المنتظم في التاريخ الملوك و الامم ، 70/9.

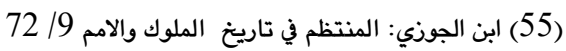

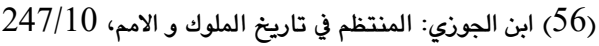

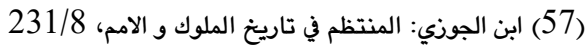

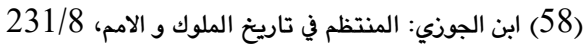

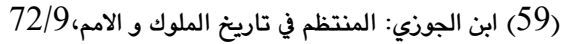

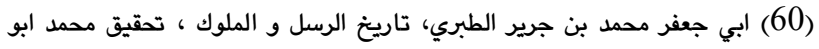

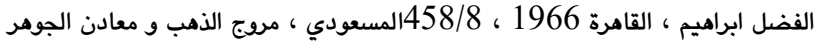

318/3،

(61) العيارون في ذلك كالصعاليك عند عرب الجاهليه و هم طبقة من المجتمع العربي

القديم اصابهم الفقر فتاقوا الى الغنى عن طريق المقامرة و الغزو و قطع الطريق اعتقادا منهم ان المال مال الله من حق المحروم ان ياخذ من الموسر عنوة و قسرا وكان الصعاليك مغامرين يتسمون بالشجاعة و لذلك عدت الصعلكة عند العرب مفخرا لانها

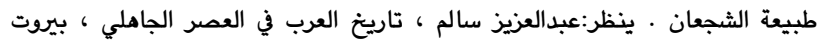
1970 ، ص440 (62) نيقولازياده : دراسات اسلامية بيروت صل1960 ، 1960 ، ص231

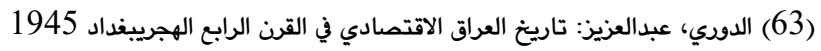

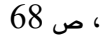
نشوء الاصناف و الحرف ص 156 - 158 ـ 154

(64) ابن الاثير: عزالدين ابي الحسن على بن محمد الشيباتي، الكامل في التاريخ،نشر دار صادر · بيروت 1965، 104 الاير: عزلين ابي الحسن

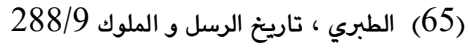

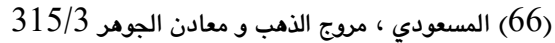



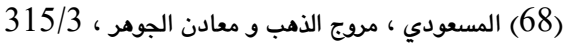

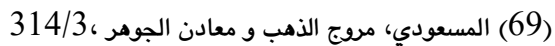


ثيانا جثاكى و ئابووريا تهخا كشتى د كومهلكهها عيراقى ل سهردهمى عهبباسى دا

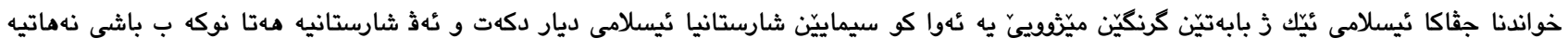
دياركن و هندهك بهريهريّن ديروكا ئيسلامى بهحسى جثاك و تهخيّن كومهلكههي يِّن جوراوجور دكهن، لهورا ئهث ثهكولينه روناهيى بهردهدهته سهر وكّ

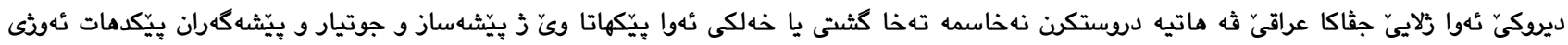

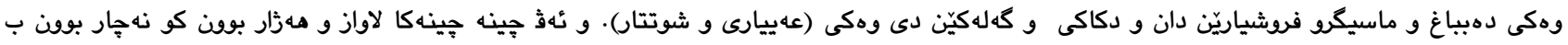

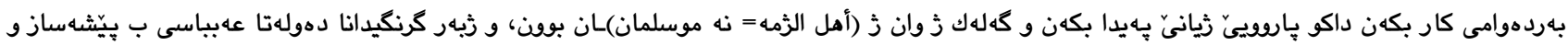

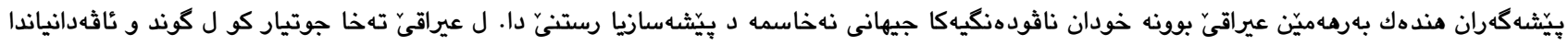
ناكنجى بوون مهزنترين تهخا جثاكيا سهردهميّ عهبباسى بيّكَ دئينان.

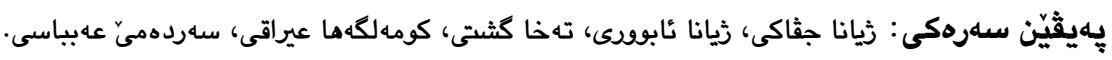

\title{
Social and Economic Life in The Public Class of Iraqi Society in The Abbasid Period
}

\begin{abstract}
:
The study of the Islamic community of important historical topics, which reveal the manifestations of Islamic civilization, which did not devote sufficient efforts to reveal and highlight the existence and highlighted some pages of our history of the bright social structure of the various layers of the Islamic community, so the research derived the article from multiple parables and address the history of the community Especially the Iraqi public class, Which includes in its composition the industrialists, craftsmen, farmers and various types of society, such as the profiteers of tanning, Hamalis, Smakin, vendors of flour, hiccups, and many others, such as grooms and rattles. This class was dominated by the characteristics of the poor class: poverty, deprivation, poverty and urgent need. Of whom are from the people of Dharma, Thanks to the patronage and encouragement of the Abbasid state to the craftsmen and craftsmen, some Iraqi industries became famous internationally, especially the textile industries, as well as farmers from villages and rural areas in Iraq who were engaged in agriculture and farming the land. This category of the public class was the majority of the population of Iraq in the Abbasid era, while the caliber were belonging to the layers of popular workers, a group of the public rushed to improve their economic conditions miserable by taking various methods of robbery and theft and theft using the weapon to achieve their goals, As well as the fugitives who are a group of the public also works in the looting and the use of ways and means of violent to achieve their goals have been active during the events of the year (197 AH / 812 AD) after the siege of Baghdad, and thus revealed Baghdad and other cities in Iraq thousands of author This is what leads to the fact that these actions are only a result of the public's suffering from the decline of their political and economic conditions. However, this class has had a great role in Iraqi society in terms of political, social and economic.
\end{abstract}

Keywords: Social life, Economic Life, Public Class, Iraqi Society, The Abbasid Period. 